
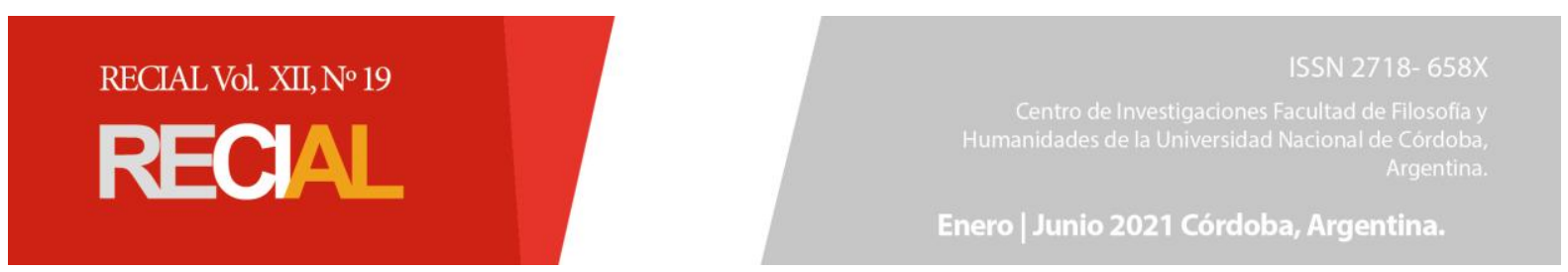

\title{
Una periodización de la presencia de Proust en la novela brasileña: Jorge de Lima, Augusto Meyer y Pedro Nava
}

Fillipe Mauro*

\section{Resumen}

La obra de Proust llegó a Brasil durante la década de 1920 y rápidamente se convirtió en uno de los temas favoritos de críticos y escritores del país. Los artículos se multiplicaron en periódicos y revistas; los poetas escribieron odas y elegías a Proust; en poco tiempo, la élite de la literatura brasileña moderna se unió en un esfuerzo por publicar la primera traducción de la Recherche en portugués. Sin embargo, una faceta de la importante circulación de Proust en Brasil permanece aún poco estudiada. Diferentes novelas incorporaron algunos rasgos importantes de la estética proustiana para expresar las más variadas visiones sobre la transformación del tiempo y de la vida en Brasil. Este artículo presentará tres casos muy representativos de este fenómeno de "reparto de una situación objetiva", como diría Fredric Jameson, en el que "todo un grupo de respuestas variadas e innovaciones creativas es posible": el tiempo perdido católico en A Mulher obscura, de Jorge de Lima (1939); el tiempo perdido regionalista en Segredos da infância, de Augusto Meyer (1949); y el tiempo perdido psicológico en Baú de ossos, de Pedro Nava (1972).

Palabras clave: Marcel Proust, Jorge de Lima, Augusto Meyer, Pedro Nava, novela brasileña

\section{A periodization of the presence of Proust in the Brazilian novel: Jorge de Lima, Augusto Meyer and Pedro Nava}

\begin{abstract}
The work of Proust arrived in Brazil during the 20's and quickly became one of the favorite themes of local critics and writers. Articles proliferated in newspapers and magazines; poets wrote odes and elegies to Proust; and, in a short time, the elite of the modern Brazilian literature joined efforts in the common goal of publishing the first translation of the Recherche in Portuguese. Nevertheless, an aspect of the important circulation of Proust in Brazil remains too little studied. Several novels absorbed the main features of the proustian aesthetics in order to express the most varied visions on the transformation of time and life in Brazil. This article will present three cases which are very representative of this "sharing of a common objective situation", as Fredric Jameson would say, where "a whole range varied responses and creative innovations is then possible": the catholic lost time of A Mulher obscura, by Jorge de Lima (1939); the regionalist lost time of
\end{abstract}

\footnotetext{
* Doctorando en Literatura Comparada (Universidad de São Paulo y Universidad París III-Sorbonne Nouvelle), Brasil. fillipe.mauro@gmail.com

Recibido 13/11/2020 Aceptado 25/03/2021
} 
Segredos da infância, by Augusto Meyer (1949); and the psychological lost time of Baú de ossos, by Pedro Nava (1972).

Keywords: Marcel Proust, Jorge de Lima, Augusto Meyer, Pedro Nava, brazilian novel

La llegada de ̀̀ la recherche du temps perdu a Brasil, que fue posible gracias a la creciente circulación de la obra de Proust en el extranjero desde el Premio Goncourt de 1919, despertó un gran entusiasmo en el mundo literario del país. Como dijo Walnice Nogueira Galvão (en Willemart, 2012, p. 12) hace unos años, "entre los años treinta y sesenta, todos nuestros críticos más importantes escribieron sobre Proust" y, "durante mucho tiempo, cualquier crítico brasileño que se respetara leyó a Proust".

De hecho, la Recherche tuvo una cálida acogida antes de los años treinta. Ya en 1925, Graça Aranha escribió el primer artículo brasileño dedicado a Proust. Un texto muy escéptico y apresurado, simplemente titulado "Marcel Proust", en el que expresa, con muy pocas palabras, su profunda desconfianza hacia la naturaleza moderna de la Recherche: "Proust no nos rejuvenece", dijo, porque, en este autor, "el viejo espíritu francés se limita al análisis de las cosas, la narración de hechos, la asociación de ideas y sensaciones" (Aranha, 1925, pp. 135-136). En 1928, el crítico Tristão de Athayde, seudónimo de Alceu Amoroso Lima, se opuso a Graça Aranha. Publicó un nuevo artículo, con el mismo título, pero mucho mejor fundado y reflexivo, cuyo objetivo era afirmar que por supuesto "Proust quería ser una novedad" (Athayde, 1928, p. 147) y que la Recherche presenta "una topografía completa y original del hombre que, ya, coloca a su autor al lado de Montaigne como un explorador del alma humana" (p. 153). En 1950, el editor del primer volumen del Bulletin de la Société des Amis de Marcel Proust (1950, p. 67) se sorprendió al enterarse de que, desde junio de 1947 (por lo tanto antes de la primera traducción de la Recherche al portugués), estos vigorosos debates proustianos de la crítica brasileña se organizaban dentro de un "Proust-Clube do Brasil" - una "hermana distante" de la asociación francesa con sede en Río de Janeiro, en el distrito de Copacabana.

Este frenesí fue similar en el campo de la poesía. En 1932, el joven poeta Jorge de Lima siguió el ejemplo de la famosa Ode à Marcel Proust de Paul Morand con su Poema a Marcel Proust. Morand (1920, p. 19) escribió: “¿Fueron de tan terribles vigilias que dejaste allí / este rosa fresco / del retrato de Jacques-Émile Blanche?"1. Mientras Jorge de Lima (1959, p. 337), por su parte, responde: "Oh mon petit Proust, / hoy tu cara lunar / en esta hermosa pintura de Jacques-Émile Blanche; / tu cara de flor nocturna / se ha extinguido, mon petit" ${ }^{\text {"2 }}$. Un poco antes, en 1928, Augusto Meyer (p. 41) siguió el mismo camino, tal vez un poco más bucólico, con su Elegía para Marcel Proust: "Flora carnal de las jóvenes que caminan por el mar. / Niebla fieltros París a través de los vidrios / Lluvia intermitente y el sol LE TEMPS PERDU"3. Incluso a principios de la década de 1980, los lectores brasileños de Proust han descubierto la pequeña antología Caderno de Proust, en la que el poeta Cláudio Murilo (1982, p. 5) nos presenta una serie de poemas que rara vez aluden a la Recherche, pero que habrían sido intensamente impregnados por su lectura: "era el ídolo de mi juventud / su retrato en la pared me recuerda / las esperanzas y sueños de convertirse en poeta / relegado a las termitas de los incunables"

En cuanto a las traducciones, la primera versión portuguesa de Du côté de chez Swann es brasileña y fue publicada el 15 de octubre de 1948 por el poeta modernista Mario Quintana. Una rara fotografía de la fachada de la librería de la editorial Globo en Río de Janeiro destaca la importancia de este acontecimiento literario (Coelho, 1950, p. 202). Los volúmenes de la Recherche ocupan cada centímetro del escaparate. En el centro, en un cartel donde los editores anuncian su "orgullo de presentar al público brasileño el nombre más importante de la literatura francesa moderna", vemos una gran reproducción del famoso retrato de Otto 


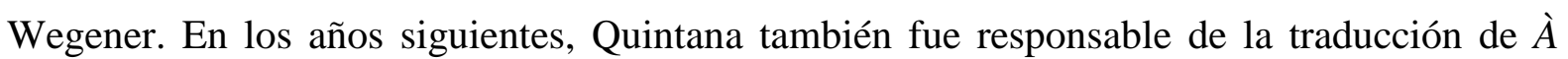
l'ombre des jeunes filles en fleurs, Le côté de Guermantes y Sodoma y Gomorra. Otros nombres conocidos del canon de la literatura brasileña moderna han participado en los esfuerzos para la traducción de los últimos tres volúmenes: Manuel Bandeira, con la ayuda de Lourdes Sousa Alencar, se encargó de La prisonnière; Carlos Drummond de Andrade estuvo a cargo de La fugitive; y Lucia Miguel Pereira completó el proyecto con su versión de Le temps retrouvé. Décadas despues, en 1993, el poeta Fernando Py publicó en la editorial Ediouro una nueva traducción completa de la Recherche. Otra tercera traducción, realizada por los periodistas Mario Sergio Conti y Rosa Freire d'Aguiar, será publicada próximamente por la editorial Companhia das Letras.

Figura 1.

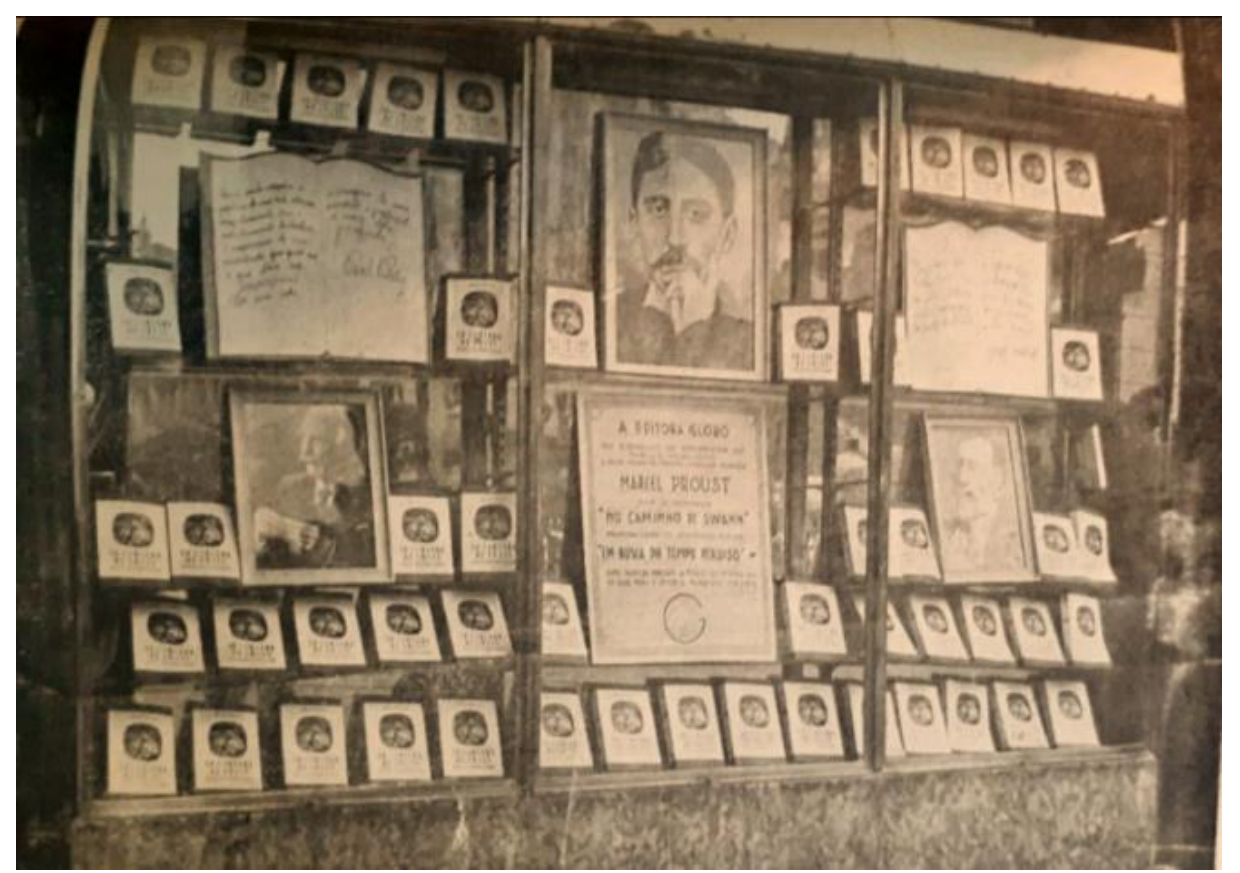

Nota. La fachada de la librería de la editorial Globo en 1948. Fuente: Coelho, 1950, p. 202.

Nada de esto es nuevo. La historia de este fenómeno de proliferación y difusión de la obra de Proust entre las élites intelectuales brasileñas está cuidadosamente documentada por la rigurosa tesis doctoral de Etienne Sauthier (2020), publicada a principios de este año por Septentrion. Desde 1993, contamos igualmente con la tesis de María Marta Laus, quien describió la diversidad y evolución de la recepción crítica de Proust entre la llegada de la Recherche en los años veinte y el golpe de Estado de 1964. Sin embargo, hay otra dimensión de la presencia de Proust en la literatura brasileña que, en mi opinión, aún no está suficientemente interpretada y que he estado describiendo durante al menos dos años como las resonancias y las apropiaciones de la estética de En busca del tiempo perdido por la novela modernista brasileña. Un tipo de narrativa que, según Antonio Cândido, tiene la vocación "compleja y contradictoria" de "asimilar con originalidad las sugerencias de las matrices culturales, produciendo a gran escala una literatura propia" (2010, p. 87).

Ese es el tema que he elegido para este artículo. No nos interesaremos por la historia de la circulación de Proust entre las élites intelectuales de Brasil ni por la historia de su recepción crítica - dos temas que ya han sido muy bien estudiados- En su lugar, nos centraremos en un estudio sobre la apropiación y resonancia de la Recherche en la novela brasileña moderna. Existen varias novelas brasileñas que citan, hacen referencia o, al menos, se impregnan de la estética proustiana. Sin embargo, considero la hipótesis de que, a lo largo del siglo XX, estas 
búsquedas tropicales del tiempo perdido no se limitaron a diversificarse, no se limitaron a multiplicarse, sino que también reflejaron diferentes visiones sobre la construcción de una identidad brasileña. En otras palabras, los diversos temas, motivos, episodios y especificidades lingüísticas que conforman el estilo de Proust se repiten en la novela brasileña del siglo XX, pero nunca sin ser incorporados y recompuestos de las formas más diversas.

Abordaré tres casos que considero los más representativos de este interesante caso de "reparto de una situación objetiva", como diría Fredric Jameson, en el que "todo un grupo de respuestas variadas e innovaciones creativas es posible" (1988, p. 179): primero, el tiempo perdido católico de A Mulher obscura, de Jorge de Lima, en los años treinta; segundo, el tiempo perdido regionalista de Segredos da infância, de Augusto Meyer, en los años cuarenta; finalmente, el tiempo perdido verdaderamente psicológico del Baú de ossos de Pedro Nava, en los años setenta.

\section{El tiempo perdido católico}

El protagonista de A Mulher obscura, una novela publicada por Jorge de Lima en 1939, es el joven estudiante Fernando, que deja la capital de su estado y regresa a su pueblo natal, la pequeña Vila de Santa Maria Madalena, con el fin de gestionar el legado de su difunto padre. La Vila de Santa Maria Madalena es una alusión a las madeleines de Proust y el autor es identificado herméticamente al principio del libro como "un judío de genio" que pasó años "en busca del tiempo perdido y lo encontró a través de lo que podemos sacar del subconsciente" (Lima, 1939, p. 26). Además del narrador de la Recherche, este personaje comienza sus recuerdos acostado, en la cama, exhausto por el insomnio que tortura sus pensamientos y que revive, "del polvo de mis extremidades insensibles", una misteriosa memoria perdida:

Hace mucho tiempo que me he acostado a dormir. Tan pronto como mi lámpara se apagó, mis ojos se cerraron tan rápido que no pude definir esa sensación agradable. Sin embargo, unos minutos más tarde, el recuerdo de las cosas, que llegó a tiempo para perturbar mi sueño, me despertó. (Lima, 1939, p. 24).

El más inatento de los lectores de Proust reconoce el origen de este pasaje de Jorge de Lima en la famosa apertura de la Recherche. Porque, como dijo el crítico Ruy Coelho en ese momento 5 , hay una dimensión tan "profundamente proustiana" en A Mulher obscura que este libro se convierte en un verdadero "pastiche de Proust" (Sauthier, 2014, p. 284). Hay otros pasajes donde notamos este esfuerzo para absorber a Proust. Poco después, Fernando recuerda su infancia en Madalena, que es análoga a la infancia del pequeño Marcel y el episodio del drama de la hora de dormir. Sin embargo, no es un Charles Swann, esnob burgués y moderno, a quien el padre del narrador Fernando invita a cenar en su casa. Jorge de Lima aclimata Proust a la premoderna región nordeste de Brasil de finales del siglo XIX y sustituye al diletante, una figura algo más probable en la Francia de la Belle Époque, por una autoridad moral, por un sacerdote:

Una noche, uno de los capuchinos invitados por mi padre a cenar con nosotros reunió a toda mi familia, amigos y sirvientes en la gran sala de estar y, después de una breve oración que ya no puedo recordar, contó a los presentes una maravillosa historia que hoy asocio con la historia de la "caída", relacionada 
con las devociones del día de la aparición de San Miguel. (Lima, 1939, pp. 3132).

La maravillosa historia del arcángel Miguel, del enviado del cielo para comandar a la milicia celestial contra los demonios caídos del mundo terrenal, parece ocupar en A Mulher obscura el espacio que la Recherche dedica a la legendaria novela de Geneviève de Brabant y del caballero Golo. Las diferencias son sutiles, pero sintomáticas. El pequeño Marcel sigue a Geneviève de Brabant y al cruel caballero Golo a través de las proyecciones de una linterna mágica que, a pesar de su poder para encantar las paredes de su habitación, pierde rápidamente la capacidad de distraerlo del tormento de abandonar a la madre para irse a dormir. Además, Fernando escucha la historia del monje con su familia, "en un viejo sofá de madera de jacaranda", sin quedarse sin el beso materno, la cena que los padres de Marcel le prohíben en Combray (Lima, 1939, p. 32). "Por fin, respiramos", dijo la madre aliviada en la Recherche (RTP, I, p. 11). Mientras que solo después de la fiesta Fernando se va a la cama. La vacilación con la linterna mágica de Combray se convierte en A Mulher obscura en deslumbramiento inmediato con un tipo de modernización, la llegada de lámparas incandescentes en la Vila de Santa Maria Madalena:

en el momento de la cena, habíamos encendido por primera vez una gran lámpara incandescente cuya luz verdosa, más viva que la luz eléctrica, sigue siendo hoy suave y deliciosa para mis ojos cansados de varios espectáculos. (Lima, 1939, p. 32).

En esta "noche inolvidable", la lámpara provoca en Fernando la sensación de una "claridad muy hermosa" que diría "robada de un cometa". En el salón del hotel familiar, nació un "mundo brillante y bueno". Marcel, por su parte, prefiere ser abandonado en su oscura habitación donde el hábito, las sucesivas esperas, servirían al menos para adormecerlo y hacer desaparecer el sufrimiento causado por la distancia de su madre. Pero jamás omite el gran placer estético que le dan las coloridas figuras y las compara con vidrieras góticas, "apariciones multicolores" e "irisaciones impalpables" (RTP, I, p. 9), tan "sobrenaturales" como las nuevas luminosidades "magnánimas" de Fernando.

Si la Recherche sigue siendo, como dijo Bernard Brun, una "novela de amor" (en Bouillaguet, 2014, p. 61), no se puede decir lo contrario con respecto a A Mulher obscura. La grande trama de este libro es el redescubrimiento de Constança por Fernando a su regreso al pueblo de Madalena. Constança, una joven tímida, casta y frágil que había sido el amor de la infancia del narrador antes de irse a vivir en" habitaciones al lado de grandes avenidas llenas de gente", antes de irse a disfrutar del placer carnal en "cabarés", antes de ser arrestado "como un subversivo" porque guardaba "algunas novelas rusas" en casa (Lima, 1939, p. 23). Antes, como sea, de culparse por "fallas, desobediencias, reconciliaciones y nuevas amenazas" (p. 25). Constança, que es sobrina de un sacerdote, Josué, el guardián moral de Fernando, y que desempeñará el papel de una especie de inmaculada Odette de Crecy, cuyo amor puro será engañado por el hedonismo de este Swann bohemio e irresponsable. A este idilio Jorge de Lima supo proporcionar un sustrato artístico que sensualiza el amor. Un minueto que Fernando escucha gracias al redescubrimiento de la caja de música de su padre y que inmediatamente asociará a su amor juvenil por Constança:

De cuatro compositores, el pequeño instrumento tocaba unos cuantos compases con tal encanto que permanecimos deslumbrados durante todo el día, desde el momento en que lo descubrimos. Entre todas estas pequeñas piezas de música, fue un minueto lo que más nos conmovió. Era una armonía 
emocionante, a veces sutil y pura, con ciertos gestos y movimientos de Constancita, a veces serena y majestuosa, como quería ser cuando creciera, junto a mi compañera, como un guía que la conduciría por mis caminos. (Lima, 1939, p. 37).

El minueto de Jorge de Lima y la breve frase de la sonata de Vinteuil en Proust, que es "el himno nacional" (RTP, I, p. 215) del amor de Swann por Odette, el símbolo de la gloriosa fase de la pareja en el salón Verdurin:

Con su lento ritmo lo encaminaba, ora por un lado ora por otro: hacia una felicidad noble, ininteligible y concreta. Y de repente, al llegar a cierto punto, cuando él se disponía a seguirla, hubo un momento de pausa y bruscamente cambió de rumbo, y con un movimiento nuevo, más rápido, menudo, melancólico, incesante y suave, lo arrastró con ella hacia desconocidas perspectivas. Luego, desapareció. (RTP, I, p. 207).

Sin embargo, Fernando aniquilará la esperanza matrimonial de Constança. Esta es la tragedia de esta novela. El narrador se reserva su deseo a otras mujeres mayores, casadas, imposibles y más voluptuosas. Se abandona, por ejemplo, a la tentación de la excéntrica burguesa Irina y de Hilda, la seductora esposa de un industrial inglés y aburrido. Una mujer espiritual, rica y gran lectora de Shakespeare, que simboliza un mundo de prestigio, placer y buen gusto al que Fernando desea pertenecer. Es en sus ventanas, y no en las de Constança, que Fernando llamará tarde en la noche:

Así que, soñador, había llegado frente a las puertas altas de la villa, en la que flotaba el balcón de Hilda. Volví dos pasos hacia atrás, sólo tenía una ventana iluminada y era la ventana de la habitación de Hilda. [...] Así que en un momento, como si me hubieran inducido fuerzas obsesivas, subí al balcón y me di cuenta de que estaba en la habitación de Hilda. Me sorprendió que mi impulso y la falta de pensamiento me lanzaran donde jamás podría imaginarme un día. (Lima, 1939, pp. 250-251).

Fuerzas obsesivas que son, como todo lo demás en A Mulher obscura, como el insomnio de Fernando, como la lámpara incandescente de la casa de infancia, como el minueto, el equivalente preciso de los temas y episodios más conocidos de Du côté de chez Swann. La invasión de la habitación de Hilda Brandt, que es tan similar en forma y tan distante en su sentido de la torpe invasión de la ventana de Odette de Crecy por Charles Swann:

Se empinó y dio un golpe. No oyeron, y entonces volvió a llamar, y la conversación cesó. Se oyó una voz de hombre, y Swann se fijó en ella, por si distinguía de qué amigo de Odette era, que preguntó:

—¿Quién es? (RTP, I, p. 270).

Swann siguió golpeando la ventana hasta que dos caballeros desconocidos abrieron con una lámpara en la mano y no pudo reconocer la habitación que estaba seguro de pertenecer a Odette: "se había equivocado, y llamó en una ventana de la casa de al lado" (RTP, I, p. 271). Además, el narrador de la Recherche juega el papel de protagonista de un importante episodio de desajuste entre su imaginación erótica y las posibilidades reales de disfrutar del placer. Ante todo porque, en sus repetidos esfuerzos por demostrar fuerzas constantes y universales del alma humana, transformará su propia experiencia amorosa en una extensión, 
incluso a veces en una homología del amor de Swann. Al final de su estancia en Balbec, recibe la emocionante invitación de Albertina para visitarla sola por la noche en su habitación de hotel. Una invitación sorprendente que, debido a su confusión entre intimidad y promesas, causa un trágico paso en falso del deseo: "de pronto, en la Albertina real, en la que veía todos los días, en la que yo me figuraba tan llena de prejuicios burgueses y tan franca con su tía, acababa de encarnarse la Albertina imaginaria" (RTP, II, p. 284).

El narrador se inclina sobre la cara de Albertina, sin su consentimiento. Ella le advierte que llamará a los lacayos si continúa: "Deténgase o llamo" (RTP, II, p. 286). Él persiste, atraído por el deseo de conocer "el olor y el sabor de aquel misterioso fruto rosado" (p. 284). Él sigue al amigo Bloch, según el cual "podía uno poseer a todas las mujeres" (p. 286). Y Albertine cumple su promesa anterior, tirando de la campanilla "con todas sus fuerzas" ( $\mathrm{p}$. 286).

Fernando no se equivoca con la ventana y no vacila frente a la vulnerabilidad de su amada. Toma a la mujer dormida "junto al tronco", "en sus brazos", "con cuidado... Brutalmente... ferozmente", hasta que "Hilda abrió sus ojos alucinados" y "cubrió el cuerpo con las sábanas, se despertó sobresaltada, con los ojos temblando de indignación”. “¡Fuera!”, grita ella. Fernando salta por la ventana, huye de las sombras que lo acechan, se esconde en una plantación de caña de azúcar y termina siendo expulsado de Madalena, su pueblo natal (Lima, 1939, p. 253).

Mientras que el narrador de Jorge de Lima lleva una vida hedonista, culminando en la violenta purga de Madalena, Constança muere de tuberculosis en un sanatorio. Ella sabe que va a morir y escribe una carta a Fernando en la que le dice "adiós" y promete encontrarlo un día "para siempre" (Lima, 1939, p. 197). Al principio, el narrador reacciona de una manera completamente indiferente: "el primer día de la muerte de Constança fue como los demás" (p. 199). Sin embargo, el tío de la niña comienza a verse "seco" y él mismo llega a la conclusión de que la enfermedad de Constanza "de repente empeoró" por su culpa (p. 188). Constança se convierte gradualmente en el fantasma de su vida. Simboliza el arrepentimiento del narrador y provoca un gran cambio en su personalidad. Según el sacerdote, la muerte de Constança llevará a Fernando, este "sórdido Caín", este "desafortunado discípulo", a buscar su "remisión" (p. 291), a descubrir la "verdadera sabiduría", que significa "saber vivir cristianamente" (p. 282).

Sin embargo, todo este vocabulario de la liturgia católica que se funde con los pastiches de la Recherche no puede ser ignorado. Por el contrario, demuestra que el primer momento de apropiación de la estética proustiana por la novela modernista brasileña se refiere a una literatura católica que fue, según Antonio Cândido (2010, p. 105), una de las "principales opciones ideológicas" del arte brasileño en la década de 1930, a menudo con "extensiones políticas en la Acción Católica" y otras asociaciones de "extrema derecha".

El tiempo perdido de Fernando es un tiempo de perdición, es decir, de corrupción y decadencia moral. Su tiempo recuperado es un pesar: "De repente, sospeché que mi egoísmo cuasi-sexual, al menos erótico, había sido la causa de la muerte de Constança" (Lima, 1939, p. 202). Además, la superación de la patología del amor, muy lenta y jamás completa en Proust, siempre en forma de artificio de la imaginación, presenta en Lima los contornos religiosos de un perdón:

Sin embargo, me liberé de este primer grado de obsesión y el recuerdo de mi amada resurgió con su flexibilidad y belleza. Los momentos de tranquilidad, la contemplación de su magnificencia y la bondad surrealista fueron mi felicidad. (Lima, 1939, p. 202). 
La Constança de Jorge de Lima es una personificación de la fe. Este autor distorsiona el "tiempo perdido" de Proust en forma de momentos en los que la doctrina cristiana se aleja en favor de la vida mundana. Esta fue la lectura de Jorge de Lima de la biografía de Proust. En un ensayo bastante sintomático publicado en 1929 y traducido unos años más tarde al francés, Jorge de Lima definió a Proust como un "religioso místico y creyente" que dio testimonio de ternura y bondad innatas (p. 25). Un modernizador del antiguo espiritismo de Maine de Biran o de la vida contemplativa de Teresa de Ávila. El tiempo, casi un personaje en la Recherche se funde en la lectura de Jorge de Lima con la propia imagen de la divinidad: "Proust pertenece a la raza de estas personas preocupadas, que siempre son vecinas de lo sobrehumano, que es un paso hacia Dios" (p. 15). Según Jorge de Lima, debido a su frágil salud, sus hábitos sociales, sus orígenes judíos y su homosexualidad, Proust "también subió su calvario", así como el "Cristo, muriendo" (p. 61). Por lo tanto, la Recherche no sería más que una "tragedia sentimental", el reflejo de una "batalla dura y gigantesca" que se esconde bajo la "apariencia decorativa de la vida burguesa" (p. 51).

\section{El tiempo perdido regionalista}

Las novelas que Augusto Meyer publicó entre finales de los años 1940 y 1960 son menos palpitantes que la de Jorge de Lima. En lugar de un narrador que presenta la historia de su juventud en forma de una trayectoria hedonista, impregnada de fallas morales de las que se considera culpable y de las que se arrepiente, para reconciliarse con los valores cristianos, todo esto como una confusión entre el tiempo perdido y una especie de tiempo de perdición, el lector encontrará una delicada y fina colección de recuerdos de la infancia y la juventud en la región de las pampas brasileñas. A través de los pequeños capítulos de estos libros, encontramos principalmente recuerdos típicos, es decir, recuerdos de las costumbres locales, de la organización de la vida social, de los aspectos arquitectónicos de la región y de las peculiaridades de su paisaje natural, como su clima y vegetación.

El primer volumen, Segredos da infância, fue publicado en 1949. Incluye once capítulos que recorren la infancia del narrador, desde su edad más temprana en Cerro d'Árvore, la estancia familiar en la ciudad de Encruzilhada, hasta las vacaciones en São Leopoldo. Lo describió como "una ciudad tranquilla con aires de pueblo" donde, "en caminos de arena o tierra blanda", "a la sombra de los plátanos", uno vive el tiempo de un "descanso idílico" (Meyer, 1949, p. 126). Así como Combray y sus "caminos desiertos", su "río, claro y corretón", su "cielo vacante" y sus "nubecillas perezosas" (RTP, I, pp. 109-110). La novela se abre con dos párrafos aislados del resto del texto por un gran espacio en blanco, lo que sugiere que deben ser entendidos como los argumentos de su línea de investigación de la infancia perdida. En el primero de estos párrafos, encontramos una frase muy proustiana y categórica, que permite presagiar su aventura a través del espacio del olvido: "la MEMORIA [sic] de la infancia es una isla perdida" (Meyer, 1949, p. 11). El narrador promete navegar a esta isla. Después de la "incertidumbre de los compases iniciales", prevé un verdadero "destello de descubrimientos imprevistos" (p. 11). Una memoria capital que definirá, inmediatamente, en el segundo párrafo, como un gesto de:

Volver a la raíz de la vida, revivir esta fase donde somos al mismo tiempo todas las cosas, la cuna, el amanecer, la campana y la ola, una parte integral de la totalidad, sin individualismo exclusivista. En el principio, era la dispersión. (Meyer, 1949, p. 11).

Este sentido de pertenencia a un complejo dinámico en oposición a una individualidad estable y fija es la base de la visión estética de Proust: "Cada día atribuyo menos valor [...] a 
la inteligencia, porque cada vez más creo que es impotente para esta recreación de la realidad que es todo el arte" (CSB, p. 216). Así, Proust quiere distinguir al narrador modernista, que integra y unifica fragmentos de un mundo dinámico desde su perspectiva subjetiva, del narrador del linaje realista, incluso naturalista, que él llama "intelectual" y que es el arquitecto de tipos sociales y personalidades in abstracto. Lo que Meyer propone como "integración a la totalidad" es equivalente a lo que Spitzer llamó "razón ordenadora" para la diversidad en Proust, el narrador que observa todo en movimiento y desde una posición elevada (1970, p. 400). Todas las cosas, la cuna, el amanecer, la campana y la onda", que son los múltiples fragmentos que el narrador de Segredos da infância, desde un punto de vista igualmente alto, intentará articular con su esfuerzo de rememoración. La dispersión ocurre "en el principio", una expresión bíblica que expresa el estado primordial del universo en el cual el escritor desea intervenir para establecer su orden y su razón. El detonador de esta intervención aparece entonces en el tercer párrafo del libro:

Mi primer recuerdo es una vieja pared, en el jardín de una casa indefinible. Había varias heridas en el yeso y terciopelos de musgo. Una milagrosa mancha verde y húmeda, suave al tacto, casi irreal en su belleza libre. Cierro los ojos y ella me llena de luz, como una advertencia de la vida testaruda. (Meyer, 1949, p. 11).

Debido a su naturaleza "milagrosa", sus efectos "irreales" y su capacidad para producir una "belleza libre", que anuncia una "vida testaruda", es decir, una existencia que se creía perdida, pero que persiste e insiste bajo la conciencia, el narrador de Meyer intenta transformar la antigua pared y sus terciopelos de musgo en desencadenantes de la memoria, así como las madeleines que el narrador proustiano sumerge en la taza de té y que causan un "placer delicioso", revelando una "esencia preciosa" (RTP, I, p. 44). En Meyer, el recuerdo de la antigua pared "llena de luz" la oscuridad interior de los ojos cerrados; en Proust, las madeleines muestran que ella, el alma que busca, "es justamente el país oscuro por donde ha de buscar" para" introducirla en el campo de su visión" (p. 45). Sin embargo, el narrador de Proust no guarda un recuerdo consciente del sabor de la madeleine: "hacía ya muchos años que no existía para mí de Combray más que el escenario y el drama del momento de acostarme" (p. 44). Esta es precisamente la naturaleza milagrosa de este fenómeno. Una acción física absolutamente inesperada actúa sobre el cuerpo (el sabor de la madeleine, así como el paso en falso en los adoquines de los Guermantes y el sonido de la cuchara sobre el plato) y despierta la conciencia de las experiencias que habían sido capturadas por los sentidos pero que se perdieron en la oscuridad del alma. Es por eso por lo que el narrador proustiano habla de un alma "superada por sí misma" (p. 44). La memoria debe, por lo tanto, desarrollarse para revelarse.

Meyer intenta expresar una convicción similar, pero sus imágenes de recuerdo aún son limitadas. La vieja pared es su "primer recuerdo". Lejos de ser lo que se ha perdido por la memoria y que la suerte restaura a través de los sentidos, la vieja pared de Meyer es el primer recuerdo que aún sobrevive. Su narrador sabe muy bien dónde pone un pie y la palabra "recuerdo" no podría ser mejor empleada: aun distante, este recuerdo permanece impregnado de la conciencia del narrador, así como el terciopelo de musgo se une a las heridas del yeso. Esto no es lo que el narrador ha perdido; al contrario, es lo que ha permanecido y se está recuperando voluntariamente.

Incluso el narrador de la Recherche muestra una gran desconfianza por los recuerdos de la primera infancia en la medida en que son "exteriores" a la conciencia y son conocidos solo "por lo que los demás cuentan" (RTP, II, p. 313). No hay ningún milagro real en Meyer, aunque nos diga lo contrario. En este sentido, ¿dónde está el evento inesperado? ¿Cuándo 
ocurre la revelación de una coincidencia? En un conocido artículo sobre la herencia proustiana en la literatura brasileña moderna, Tania Franco Carvalhal argumentó que las novelas memorialistas de Meyer se desarrollaron de acuerdo con "memoria involuntaria, causada por un estímulo sensorial" (2005, p. 428). Pero la crítica no dice jamás cuál es este estímulo sensorial. Y no lo dice simplemente porque son escasos y no son en absoluto importantes en Segredos da infância.

Un caso importante de estímulo sensorial en Segredos da infância, a menudo asociado con la memoria involuntaria de Proust, es el minuano, un viento fuerte, frío y seco que se precipita durante el invierno en la región sur de Brasil. El "viento del campo", una "voz tan grave que llegaba a ser aterradora" y que, cuando el narrador "cruza los campos de la frontera" de nuevo, como una "varita mágica", restaura una "cadena entre el hombre y el niño" (Meyer, 1949, p. 12). Sin embargo, rápidamente nos damos cuenta de que esta memoria carece del aspecto sorprendente que motiva el fenómeno de la memoria involuntaria. Un acontecimiento milagroso es algo que no se explica por leyes naturales. Se trata de lo que, como dijo Leibniz, no se puede prever por el razonamiento porque parte de una orden general que lo supera (1995, p. 55). Revisitar la pampa, sentir de nuevo el viento minuano y recomponer la imagen de la infancia vivida en este ambiente es un recuerdo que puede explicarse de forma natural. Es una conexión lineal, incluso análoga, "entre el hombre y el niño". Lo que no puede explicarse por las leyes naturales es un narrador que subconscientemente revive las aceras de Venecia cuando hace un paso en falso en las aceras de París, y que, precisamente por esta razón, reuniendo en su subjetividad lo que naturalmente habría permanecido separado, establece un orden general del mundo. Otro crítico, Paulo Bungart, interpretó la memoria del viento minuano como "una especie de madeleine meyeriana, como un hecho crucial que guiará la narrativa de sus memorias y dará sentido a otras manifestaciones" (2014, p. 370). De hecho, la imagen del viento minuano es omnipresente. Sin embargo, parece ser más bien una alegoría, un leitmotiv de la infancia y no exactamente un recuerdo inesperado, marcado por la sorpresa.

La diferencia es notable entre esta forma consciente de recuerdo y otras escenas de revelación inesperada de la memoria inconsciente en algunas novelas posteriores. En la ficción memorialista brasileña posterior, nos damos cuenta con toda claridad de lo que Genette llamó el mecanismo "detonador" de la Recherche: una "impresión sensorial" que causa una "explosión", una "reacción en cadena" de analogías y evocaciones metafóricas (1972, p. 56). Los "ojos cerrados" que inauguran la novela de Meyer son un paso voluntario de un narrador que siempre ha sabido a dónde deseaba llegar. Esto es completamente diferente del "placer delicioso" de Proust, que "invadió" a su narrador "sin noción de lo que lo causaba" (RTP, I, p. 44).

Estos recuerdos conscientes de Meyer explican el aspecto descriptivo, incluso etnográfico de las imágenes de los recuerdos de Segredos da infância. Constituyen una especie de álbum fotográfico que se encuentra en el fondo de un sótano y con el que se pinta una imagen variada, pero estática, de las escenas de una vida. Sin el mecanismo "detonador" de Proust no hay una "reacción en cadena" que sea posible y la novela de Meyer termina siendo relegada a la condición de una reunión de episodios y paisajes dispersos:

Tomábamos la primera comida en la sala de estar en la planta baja, junto a las ventanas enrejadas que daban a la calle. El viejo Sampaio, padre de Aparício, frente al edificio, al otro lado de la acera, abría las puertas de su tienda en un monólogo, con sus grandes bigotes retorcidos. El señor Rafael iba a esperar el tranvía a caballo en la esquina. Las criadas y amas de casa charlaban con escobas en sus manos y, una vez que el piso rústico fue limpiado, recogían su basura ... (Meyer, 1949, pp. 34-35). 
El imperfecto de Meyer, tiempo verbal hegemónico en su novela, está cerca solo desde el punto de vista formal del que Proust alabó tanto en Flaubert y que cumple la función de reportar "la vida entera de las personas" (CSB, p. 590). El eterno imperfecto que permite al narrador prolongar las cosas sin que sus personajes jueguen un papel activo en la acción. Su significado es, sin embargo, absolutamente diferente en Segredos da infância. No se utiliza para crear un continuo y así asegurarse de que una visión total no se interrumpa, es decir, para que pueda al mismo tiempo revelar las transformaciones que ocurren en los personajes a lo largo del tiempo y resaltar los cambios en la perspectiva del narrador. Más que un novelista, vemos en este libro al folclorista que Augusto Meyer fue la mayor parte de su vida, un etnógrafo de las costumbres y tradiciones de su región. Moviliza esfuerzos para recuperar escenas cuya memoria aún despierta su ferviente admiración. Tan pronto como son presentados sus personajes desaparecen. Su única función es ilustrar y justificar una realidad subjetiva que el narrador desea revelar, como una enciclopedia íntima. El viejo Sampaio, que hablaba solo; el señor Rafael, que todavía esperaba su tranvía; las amas de casa, que charlaban mientras limpiaban; y todos los demás seres de esta novela - el narrador de Meyer no les atribuye ninguna profundidad psicológica, nunca les recupera para resaltar las transformaciones abruptas y sorprendentes que afectan a la personalidad o las especificidades físicas. Además (lo más importante), no permite que ninguno de ellos inspire una reflexión sobre la esencia del amor, de las artes o de las formas de conocimiento de la vida. Es el narrador quien refleja los personajes de arriba a abajo; no al revés.

Un personaje secundario, por ejemplo la humilde lechera que se sube al vagón de tren durante el agonizante viaje a Balbec para vender café con leche, es suficiente para que Proust sensibilice al narrador, altere su subjetividad, multiplique sus puntos de percepción de la vida y luego lo lleve a desarrollar una visión compleja sobre la condición del amor, donde el objeto del deseo pierde su individualidad para convertirse en el punto convergente de impresiones de un lugar virtual, una abstracción de un espacio cuya esencia resulta inaccesible:

Esa muchacha que aún vislumbraba yo conforme el tren aceleraba su andar, era como parte de una vida distinta de la que yo conocía, separada de ella por una orla, y donde las sensaciones provocadas por las cosas no eran igual y salir de allí me era morir. (RTP, II, p. 18).

Sin embargo, en Meyer, algunos personajes importantes, como la "impresionante figura" del sacerdote Lanz, están limitados a pequeñas anécdotas, a descripciones físicas, y permanecen confinados dentro de capítulos cuyo único vínculo de comunicación son las costumbres, estilos de vida y formas de organización social de la región de las pampas. Este clérigo, "ampliado por su sotana, con las manos de largos dedos aristocráticos apoyadas en la mesa", recibe en su escuela secundaria al joven Augusto y a su hermano Henrique para una entrevista. Pero el narrador solo recuerda la silueta de su cuerpo después de "un gran esfuerzo de memoria". Todo lo que queda de la "figura impresionante" del sacerdote Lanz es su "gran tamaño, la envergadura un tanto severa de un hombre autoritario", que "fueron mitigados por una voz muy suave y por el hábito de caminar con la espalda doblada, como si estuviera doblado por el peso de varias preocupaciones" (Meyer, 1949, pp. 107-108). Las dos únicas contradicciones, las dos únicas características de complejidad de este carácter conservan un aspecto físico: la envergadura severa y la voz suave; el gran tamaño y el caminar encorvado. Después de eso, todo en el alma de este jesuita es consistente con su figura. Pide a los dos chicos que lean pasajes de libros para comprobar su fluidez retórica. Una vez satisfecho, a punto de aceptarlos en la escuela secundaria con un lacónico "muy bueno, muy bueno", el sacerdote "sonríe, complaciente". Esta complacencia es un aspecto que ya habitaba en secreto 
la esencia del personaje y que el narrador, de manera realista, conociéndolo de antemano, simplemente revela al lector. No es el producto de una transformación de un ser en el tiempo, mucho menos un cambio en el ángulo de observación, una mutación de la perspectiva del narrador o una frustración como la desilusión del joven Marcel durante el matrimonio de la hija del doctor Percepied, cuando descubre que la señora de Guermantes, inicialmente imaginada como una deidad atávica de la Francia carolingia, tenía en verdad "una nariz grande", "ojos azules y penetrantes" y una "chalina hueca de seda color malva": "sí, era ella. Muy grande fue mi desencanto" (RTP, I, p. 172). Meyer no ofrece el tiempo y la duración necesarios para eso. La descripción de la oficina del sacerdote Lanz es un ejemplo impecable del realismo atmosférico que Auerbach identifica al estilo de Balzac (1968, p. 465) y ella evoca todo lo que Proust reprendía en el canon naturalista francés desde los bocetos del Contra Sainte-Beuve, es decir, desde los principios de la elaboración de la Recherche:

La oficina es estrecha y oscura, como un pasillo. Un hombre alto, muy pálido, con una nariz de águila, ojos de una penetración punzante, una sonrisa clara y abierta a pesar de la expresión cansada. (Meyer, 1949, p. 107).

Como dice Balzac en su famosa descripción de la pensión de la señora Vauquer en el Papá Goriot: "toda su persona implica la pensión, así como la pensión implica toda su persona" (1976, p. 54). En Meyer, el "gran tamaño" y la "envergadura un tanto severa" del sacerdote Lanz explica la oficina "estrecha y oscura", así como la oficina implica a su persona. En relación con ambos casos, Proust podría decir que "el arte que pretende parecerse a la vida, al suprimirla, elimina la única cosa preciosa" $(C S B, 1954$, p. 80). La única cosa preciosa que es la intuición de una verdad, la percepción de una esencia.

\section{El tiempo perdido psicológico}

Marcel Proust y la Recherche son citados con gran naturalidad por los memorialistas de la década de 1970. Hemos visto que Jorge de Lima, durante la década de 1930, es hermético y oscuro en su forma de hacer alusiones al autor, porque susurra a lectores aún poco familiarizados con la Recherche la referencia a un misterioso "gran memorialista" que le causó una buena impresión $(1939$, p. 26). El narrador de Augusto Meyer, por su parte, habla de forma torpe de un "libro extraño y delicioso" llamado A la sombra de las muchachas en flor, pero simplemente como un pobre pretexto para recordar los hábitos de un personaje secundario, tal vez terciario, un cierto "convaleciente Bilu" que surge y desaparece rápidamente de la narrativa y cuya única función parece ser la ilustración del clima templado de las pampas brasileñas debido a su hábito de vestir "un abrigo felpudo" para ir a la biblioteca (1966, p. 91). Todo es muy diferente en Pedro Nava, donde las referencias a Proust no están camufladas o eclipsadas, sino que son más bien céntricas y dotadas de gran profundidad psicológica.

El médico Pedro Nava fue el autor de un ciclo de novelas en seis volúmenes titulado Memórias. Su primer volumen, Baú de ossos, fue descrito por la crítica como "una de las producciones más importantes de nuestra literatura contemporánea" (Cândido, 2010, p. 124). En 1982, el crítico Wilson Martins señaló en una reseña en la revista World Literature Today que la presencia de Proust en el texto de Nava es "a veces excesiva", pero que estas "connotaciones y resonancias" lo convirtieron en un "prodigio de la literatura" y tienen el mérito de "crear un estilo 'Proustiano 'en la lengua portuguesa" (vol. 56, n. 4, p. 666). De hecho, estas "connotaciones y resonancias" son las raíces de una gran sofisticación poética. No se trata de notas al pie de página ni de meras insinuaciones, como en los dos casos que acabamos de analizar. Estas "connotaciones y resonancias" dejan de ser un simple arrebato 
de erudición para convertirse en el detonante de reflexiones sobre el funcionamiento de la vida con una rica economía lingüística.

Después del redescubrimiento de su casa de la infancia, en una bella escena de memoria involuntaria, el narrador de Baú de ossos rinde homenaje a Proust, asegurando a su lector que "todos tienen su madeleine, en un olor, en un sabor, en un color, en una relectura" y admitiendo que "cada uno fue un poco arrebatado por el pequeño Marcel porque fue él quien encontró la forma poética decisiva y punzante para este sistema de recuperación del tiempo" (Nava, 1972, p. 303). Sin embargo, este "todos" de Nava se puede leer sin ninguna dificultad como una alusión a la larga serie de memorialistas brasileños que se han dedicado a la tarea de producir una Recherche brasileña. Sin embargo, el uso de la palabra "sistema", cuyo significado filosófico es claro, indica inmediatamente que el narrador quiere ir más allá de la historia de la circulación de la novela de Proust entre las élites intelectuales de Brasil. Más que un objetivo venerado, un ideal a elogiar, la novela de Proust representa en Nava un marco de pensamiento, un conjunto de instrumentos lógicos. Incluso se podría decir un método bastante universal para desarrollar el conocimiento del hombre sobre su propio pasado. Lo que sigue al homenaje del narrador de Nava es un intento significativo de demostrar el uso de estos instrumentos y producir con ellos una imagen particular de su uso:

Esta recuperación, la percepción de este proceso de uso de la memoria (hasta ahora inerte como la Bella Durmiente en el bosque del inconsciente), conserva algo de la violencia y la brusquedad de una explosión; pero es precisamente su opuesto, ya que se concentra por precipitación y evoca de una manera crioscópica el pasado diluido, de ahora en adelante irrecuperable e incorruptible. (Nava, 1972, p. 303).

La frase de Nava, en comparación con la de sus predecesores, llama mucho la atención. No solo está interesado en la expresión de recuerdos personales, sino que este narrador hace esfuerzos para reflejar en la organización sintáctica de su frase una visión amplia de los procesos de memoria. Los recuerdos más simples, a la manera de Meyer, donde las impresiones son superpuestas por adición continua (una pared vieja, que estaba en el jardín de una casa, que tenía varias heridas en yeso, que tenía terciopelos de musgo, que eran verdes y húmedos, que eran flexibles y casi irreales) le interesan muy poco, solo en la medida en que se siente capaz de deducir leyes generales de funcionamiento de la existencia. No se trata de la acumulación de datos, sino más bien de su entrelazamiento. La figura de la hipotaxis es su gran activo. Nava no escatima en el uso de paréntesis y guiones cuya función es precisamente la de ramificar los sentidos de una idea central. Hay muchas conjunciones, con las funciones más diversas. No solo hay conjunciones adicionales, sino también causales y adversativas. El lector tiene la sensación de que la memoria es el producto de una experiencia, un lenguaje que prueba sus posibilidades de varias maneras para encontrar la medida apropiada. La enunciación se detiene para proseguir, lo que es principalmente el resultado de una vacilación entre sujetos (esta recuperación, la percepción) y de una multiplicación de sus complementos (de la violencia y la brusquedad de una explosión). El propio vocabulario evoca la idea de la experimentación y la formulación de hipótesis científicas.

Además de un hombre de letras, se lee a un médico en esta paráfrasis de las premisas proustianas de la memoria, un médico que absorbe su vocabulario de los glosarios de la química de las soluciones y de la física de las propiedades coligativas. El pasado para él es una imagen desapercibida (diluida) que guarda con él los datos transparentes del conocimiento, aparentemente invisibles. Son cambios específicos en las condiciones ambientales (crioscopia) los que conducen a la transformación de la materia latente, primero a través de la concentración, luego con la ayuda de la precipitación, hasta que producen el 
efecto sorprendente de una aparición mágica de elementos cuya existencia era desconocida hasta ese momento. Es, en definitiva, una alegoría del funcionamiento del subconsciente, que no cubre el pasado a través de una acumulación lineal de datos, sino a través de relaciones inusuales, a veces impredecibles, entre elementos distintos. En este punto, comienza a enumerar ejemplos y muestra ante los ojos del lector varios procesos diferentes, pero simultáneos, que están orquestados:

El olor del filtro de arcilla nuevo, el sabor de su agua, el silbido de la fábrica que corta las noches irrecuperables. Aroma de jugo de naranja bajo el frío ácido de las noches de junio. Las escalas de piano escuchadas bajo el sol desolado de las calles desiertas. (Nava, 1972, p. 304).

La base de estos procesos, tanto diferentes como concomitantes, es el encadenamiento de elementos materiales a través de los estímulos físicos que causan. En Meyer, propiedades como el color, la humedad y la textura de los terciopelos de musgo solo sirven para hacer la memoria más precisa y garantizar la objetividad de su narrativa. Estas son formas de descripción cuyo propósito es una imagen clara y precisa que, en sí misma, el narrador considera milagrosa. En Nava, por el contrario, podemos ver que las cosas no son suficientes por sí solas. Hay otro milagro. Se evocan entre sí a través de los diferentes efectos que producen en los sentidos. Distintos elementos como el filtro de arcilla, el agua, el silbido y la noche interesan únicamente en relación con las sensaciones que causan. Desempeñan el papel de complementos del verdadero núcleo de cada uno de los sintagmas nominales: el olor, el sabor y el ruido. La misma regla se aplica en la siguiente frase, que es en realidad una larga frase nominal cuyo núcleo constituye un fenómeno sensorial, el perfume. A partir de este, todo lo demás se desarrolla en una cadena de complementos: el jugo, que es el complemento del perfume; naranja que es el complemento de jugo, y así sucesivamente. El esfuerzo de Nava por subjetivar el mundo, imponer sensación a la materia y generalizar el alcance de la percepción es tan importante que su narrador incluso despliega complementos de otros complementos. La acidez, las noches y el mes de junio no son simplemente otros complementos del mismo núcleo de sintagma. Todos ellos son en realidad complementos de otro complemento, el frío del invierno que comienza. Incluso en la tercera frase, que no sigue la tendencia de las frases nominales y se afirma como una proposición, relega la dimensión objetiva y física - el sol desolado y las calles desiertas - a la función de complementos de lo que es, sobre todo, el sujeto, la unidad que sostiene la expresión - las notas de un piano. El narrador de Baú de ossos, imbuido de hábitos médicos, tratará entonces de formular un diagnóstico general de la compleja situación de los síntomas. Sus ejemplos terminarán con una explicación de su operación, de sus causas, que alcanzan el mismo estatus de leyes universales de funcionamiento de un organismo:

Las imágenes tiran unas a otras y así cada éxito restaura el tiempo y el espacio comprimidos y expande, dentro del que evoca estas dimensiones, reviviscencias pobladas por el olvido preparado para renacer. (Nava, 1972, p. 304).

El tiempo presente es aquí el gran garante de la imagen de ley general de funcionamiento. Tiempo por excelencia de lo que es claro, obvio y normativo, se encargará de expresar constantes del espíritu. En otras palabras, la subjetividad será abstraída, la colorida multitud de elementos dispersos será racionalizada. Pero eso no significa que sus fórmulas sean simplificaciones o procesos lineales. Por cierto, varias acciones simultáneas se suman a través de oraciones coordinadas con el fin de producir una reacción compleja, una reacción 
en cadena. En la escritura del médico Nava, la adición de cada una de las etapas de este proceso se convierte en la representación de un ciclo metabólico. Las imágenes se siguen unas a otras; su proceso produce partículas de tiempo y espacio; estas unidades, a su vez, activan regiones latentes de la conciencia que luego desencadenan la condición fisiológica que el narrador de Nava llama reviviscencias, una palabra tan impregnada de significado médico como cualquier otro fenómeno orgánico. En este tono, se podría decir que uno tiene una reviviscencia así como se tiene una neuralgia, un reumatismo o una cardiopatía. Dado que el final de todo el ciclo de vida es también su reinicio, el autor no dudará en señalar, un poco más allá, que "olvidar es un capítulo de memoria [...] y no su función antagónica" (Nava, 1972, p. 304). Olvidar no solo es inevitable; también es el partero de futuros recuerdos. Constituye un perpetuum mobile analógico que el narrador de Nava prefiere llamar a una asociación coercitiva de ideas y cuya operación demuestra así:

Pienso, por ejemplo, en libro. El espíritu errante me lleva a portada, a encuadernación. La encuadernación, a cartón. Este, a papel viejo, viejo cartonero, mendigo, un individuo miserable. Y aquí estoy... A partir de encuadernar podría haber ido a cuero en lugar de cartón. Pero el cuero fue ocultado debido a este diván de cuero de una cierta casa de la Rua da Bahia. (Nava, 1972, p. 304).

Nava concluye este importante pasaje del último capítulo de Baú de ossos con una cita de Autour de Mme Swann. Clave de oro de un soneto, aislada gráficamente y reproducida en la versión original francesa, ella enfatiza el argumento proustiano de que la memoria humana no funciona cronológicamente, "sino como un reflejo donde está alterado el orden de las partes" (RTP, II, p. 568, en Nava, 1972, p. 304). Esta es una imagen muy importante de la noción estética que promueve el narrador de la Recherche. Varias imágenes de la novela la ilustran en forma de continuas redes de analogías (Genette, 1972, p. 52), que son particularmente abundantes en el episodio de las vacaciones en Balbec, cuando el narrador descubre los paisajes marinos de Elstir y altera su comprensión del arte. Según Pierre-Louis Rey, el pintor causa una verdadera "cura" de la vocación literaria del héroe al salvarlo "de los peligros del pastiche" del escritor Bergotte a través de un "desvío de otro arte" (en RTP, II, p. 1333). La gran lección del pintor será, ni más ni menos, el esfuerzo de subjetivación del mundo material.

Sin embargo, "si, psicológicamente, no hay un límite claro entre la memoria y el olvido, estéticamente, la bahía abole diariamente toda demarcación entre los elementos" (Rey, en RTP, II, p. 1333). Así, Proust aborda objetos triviales con la misma importancia que los seres humanos, hace oscilar la visión del héroe, crea la impresión de pasaje del tiempo y termina reemplazando la "coherencia intelectual y material" por la "unidad en la mente" (Rey, en $R T P$, II, p. 1333). A medida que se acerca el final del verano y los días soleados de Balbec no son ya tan largos, el narrador se da cuenta de que el sol toma la forma de una imagen "rígida, geométrica, pasajera y fulgurante". Estas impresiones lo transforman en un" signo milagroso", una "aparición mística". Entonces, sucede su asociación con "un cuadro religioso" o incluso con un "altar mayor". El reflejo de esta escena en el hielo de la biblioteca crea, en su opinión, una sucesión de escenas pintada por un pintor primitivo en "la predela del retablo" (RTP, II, pp. 160-161). El escenario de esta serie de metonimias que componen una gran metáfora entre el horizonte marítimo y un altar corresponde a la imaginación del narrador, que racionaliza y crea conexiones inesperadas entre varios fragmentos.

Unas semanas más tarde, los días son aún más cortos y ya está oscuro cuando el narrador regresa al Grand Hotel de Balbec vacío. En este punto, la dimensión de las asociaciones se hace aún mayor y su técnica se radicaliza tanto que encuentra unidad y equivalencia entre 
elementos opuestos. Los rayos rojos del cielo de Balbec se aproximan tanto de los paisajes marinos de verano como de los colores que el narrador veía en el calvario de Combray cuando regresaba de sus paseos de la semana santa, al final del invierno. Balbec y Combray, el mar y el campo, el verano y el invierno se integrarán en la subjetividad del narrador de una manera que sería completamente improbable o al menos poco evidente en el mundo material. Estas son conexiones que, según Proust, escapan a la inteligencia. O, de manera similar, serían según Nava "raíces ocultas que atan arbustos emergentes y distantes" (Nava, 1972, p. 304). El cielo es rojo como la carne brillante que Francisca preparaba en la casa de tía Leoncia, pero también rosa como el salmón servido en el restaurante de Rivebelle. El mar que es azul como el dorso del pescado que llaman mújol, pero también es negro, denso y pulido por el frío, con la consistencia rígida de una piedra de ágata cuyas camadas ahumadas de cuarzo se parecen con vapores de un negro de hollín. Ni siquiera la habitación del hotel escapa a esta imagen. Por el contrario, este salón con ventanas redondeadas como agujeros, antiguo escenario de episodios de angustia con la interrupción de los hábitos, deja de ser una prisión para convertirse en el núcleo de esta gran alegoría marítima, su piedra angular y su clave. Cada uno de estos múltiples fenómenos se refleja en él y las referencias físicas darán paso a las referencias psíquicas. El narrador no dirá que el mundo lo contiene. Muy al contrario, será el narrador quien, acostado en su cama, navegue en el océano como un pasajero en la cabina de una embarcación. Su movimiento mental anima el movimiento material de la naturaleza.

\section{$\therefore$}

A través de estos tres casos, he intentado sugerir un nuevo enfoque para la interpretación de la periodización de la obra de Marcel Proust en Brasil, al que atribuyo el nombre de "resonancias y apropiaciones de la Recherche por la novela moderna brasileña". No tengo la ambición de competir con aquellos que han estudiado la recepción crítica de Proust en Brasil o incluso con aquellos que, al testificar de un rigor raro, han documentado la penetración de este autor entre las élites intelectuales de este país a lo largo del siglo XX. Cierro filas con Leo Spitzer cuando dice que "una de las mayores alegrías para un investigador es reunirse, al azar, a lo largo de su camino, con compañeros de trabajo de otros orígenes, y verlos abordar las mismas tareas, ubicadas en una encrucijada y asequibles en varios frentes" (Spitzer, 1970, p. 397).

Así, he intentado demostrar que una misma obra, uno mismo estilo, la estética de Proust y de su Recherche, juegan el papel de referencia artística de escritores de las más diversas tendencias de la cultura brasileña. Esta conclusión tiene al menos dos implicaciones importantes. En primer lugar, es una de las innumerables demostraciones de la importancia de la novela de Proust para la cultura modernista y de la dimensión universal de su proyecto artístico. Además, es la evidencia de que En busca del tiempo perdido contribuyó no solo con una, sino con varias visiones artísticas al violento proceso de modernización experimentado en Brasil durante el siglo XX. En otras palabras, el tiempo perdido de Proust no se convirtió en una sola forma homóloga en Brasil. Durante años, la literatura brasileña ha producido muchos tiempos perdidos: el tiempo perdido de los valores cristianos en Jorge de Lima, el tiempo perdido de la cultura regional y popular en Augusto Meyer y el tiempo perdido psicológico y subjetivo de Pedro Nava. Aun podríamos citar otras obras, como Labirinto, de Jorge Andrade; A Menina do sobrado, de Cyro dos Anjos; Província submersa, de Octacílio Alecrim. La lista es muy larga; ella da fe de la importancia de Proust para la cultura brasileña y demuestra el tamaño del desafío que espera a los proustianos brasileños. 


\section{Referencias bibliográficas}

Aranha, G. (1925). Espirito Moderno. São Paulo: Companhia Editora Nacional.

Athayde, T. (1928). Estudos: $2^{a}$ série. Rio de Janeiro: Terra e Sol.

Auerbach, E. (1968). Mimésis: la représentation de la réalité dans la littérature occidentale. Paris: Gallimard.

Balzac, H. (1976). La comédie humaine (Col. Bibliothèque de la Pléiade, t. III). Paris: Gallimard.

Bouillaguet, A. y Rogers, B. (2014). Dictionnaire Marcel Proust. Paris: Honoré Champion.

Bulletin de la société des Amis de Marcel Proust et de Combray.(1950). n.1.

Bungart, P. (2014). Augusto Meyer proustiano: a reinvenção memorialística do eu. Dourados: Editora da UFGD.

Cândido, A. (2010). Iniciação à literatura brasileira. Rio de Janeiro: Ouro sobre Azul.

Carvalhal, T. (2005). L'écriture autobiographique au Brésil : l'héritage proustien. Revue de littérature comparée, 316, pp. 419-430.

Coelho, S. (1950). Proustiana Brasileira. Rio de Janeiro: Revista Branca.

Galvão, W. (2002). Em busca de um tempo perdido. En Philippe Willemart, Educação Sentimental em Proust (pp. 11-17). São Paulo: Ateliê.

Genette, G. (1972). Métonymie chez Proust. En Gérard Genette, Figures III (pp. 41-63). Paris: Seuil.

Jameson, F. (1988). Periodizing the 60's. En Fredric Jameson, The Ideologies of theory (1971-1986): syntax of history (v. II) (pp. 178-208). Minneapolis: University of Minnesota Press.

Laus, M. (1993). A Recepção crítica da obra de Marcel Proust no Brasil (Tesis doctoral). Porto Alegre, Universidade Federal do Rio Grande do Sul.

Leibniz, G. (1995). Discours de métaphysique suivi de Monadologie. Paris: Gallimard.

Lima, J. (1929). Proust. En AUTOR, Dois ensaios (pp. 11-83). Maceió: Casa Ramalho.

Lima, J. (1939). A Mulher obscura. Rio de Janeiro: Livraria José Olympio Editora.

Lima, J. (1959). Poemas Escolhidos. En AUTOR, Obra Completa (Vol. I) (pp. 323-339). Rio de Janeiro: José Aguilar.

Martins, W. (1982). Memoirs. World Literature Today, 4(56), 666.

Meyer, A. (1928). Giraluz. Porto Alegre: Livraria do Globo;

Meyer, A. (1949). Segredos da infância. Porto Alegre: Editora Globo.

Meyer, A. (1966). No tempo da flor. Rio de Janeiro: O Cruzeiro.

Morand, P. (1920). Lampes à arc, avec un dessin de l'auteur. Paris: Au Sans Pareil.

Murilo, C. (1982). Caderno de Proust. Rio de Janeiro: Livraria José Olympio.

Nava, P. (1972). Baú de ossos. Rio de Janeiro: Sabiá.

Proust, M. (1987-1989). À la recherche du temps perdu (col. Bibliothèque de la Pléiade, edición de Jean-Yves Tadié, cuatro tomos). Paris: Gallimard.

Proust, M. (1971). Contre Sainte-Beuve précédé de Pastiches et mélanges suivi de Essais et articles (col. Bibliothèque de la Pléiade, edición de Pierre Clarac). Paris: Gallimard.

Proust, M. (1954). Contre Sainte-Beuve. Suivi de Nouveaux Mélanges (edición de Bernard de Fallois). Paris: Gallimard.

Sauthier, E. (2020). Proust sous les tropiques. Lille: Presses Universitaires du Septentrion.

Spitzer, L. (1970). Études de style. Paris: Gallimard. 


\section{Notas}

1 "Étaient-ce de si terribles veilles que vous y laissâtes / cette rose fraîcheur / du portrait de Jacques EmileBlanche?",

2 "Ó mon petit Proust, / hoje o teu rosto de lua / dêsse quadro bonito de Jacques Emile Blanche / o teu rosto de flor noturna / se apagou, mon petit”.

3 "Flora carnal das raparigas passeando á beira-mar. / Bruma esfuminho Paris pela vidraça / Intermittencias chuva e sol LE TEMPS PERDU”.

4 "Foi o ídolo na minha juventude. / Seu retrato na parede lembra / esperanças e sonhos de ser Poeta/ relegados ao cupim dos incunábulos".

${ }^{5}$ Fue Antonio Cândido quien guardó el recuerdo de estas impresiones de Ruy Coelho y se lo confió al investigador Etienne Sauthier en una entrevista el 10 de enero de 2011. 